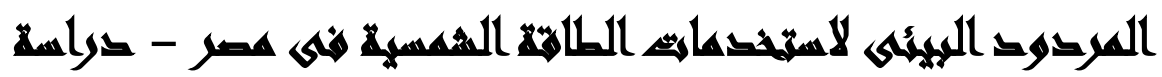

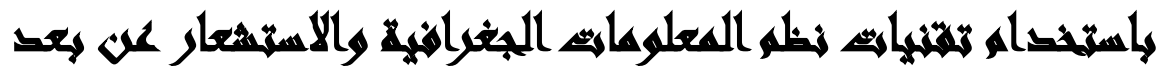

[11]

عبد العزيز عبد اللطيف(')- معوض بدوي معوض(')-- هبة الله فتحي محمد

( ) كلية الآداب، جامعة عين شمس الطيف

\author{
المستخليه
}

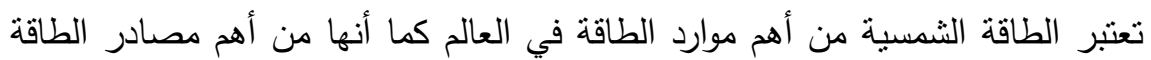

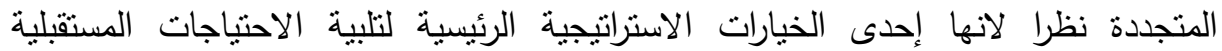

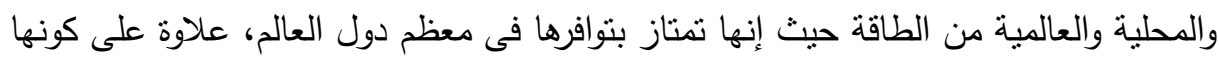

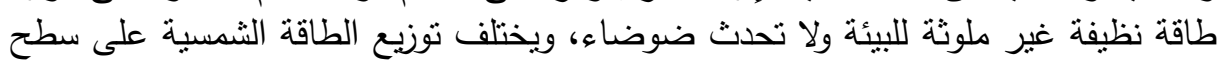

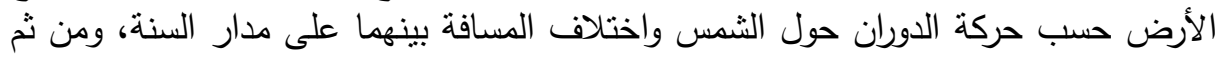

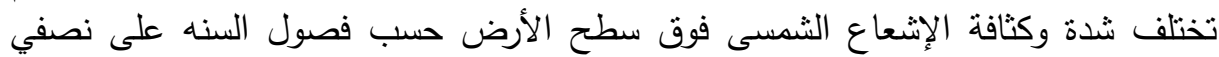

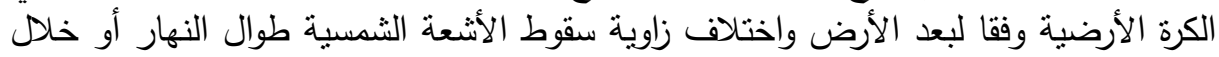

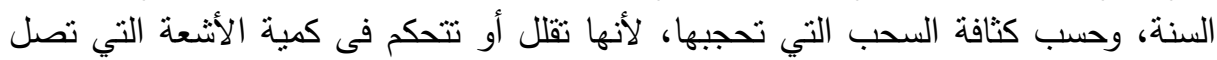

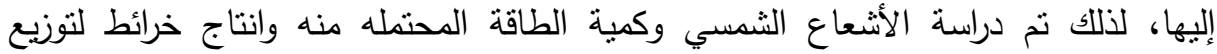

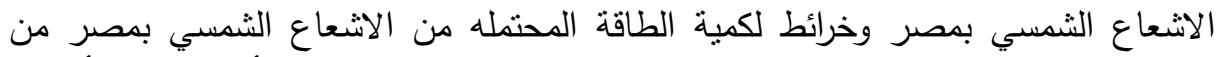

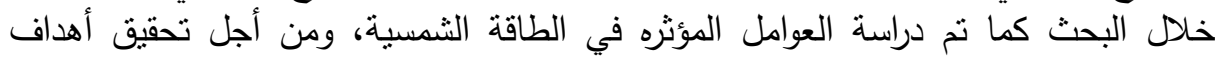

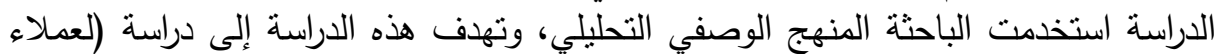

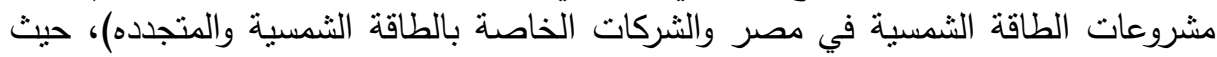

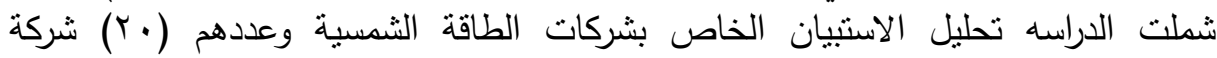

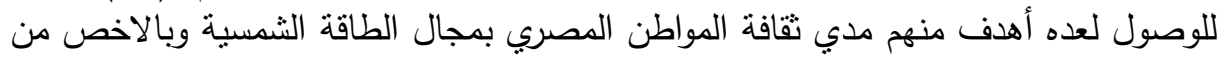

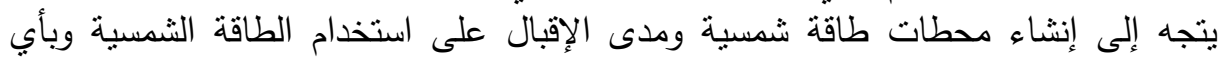
المجالات يتم الاستعانة بالطاقة الثمسية بدلا من الطاقة التقليدية، كما نم دراسة الاستنيان

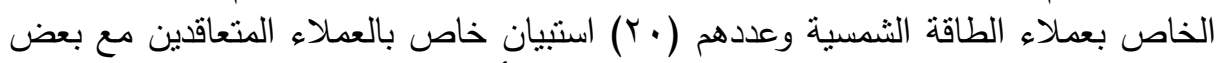

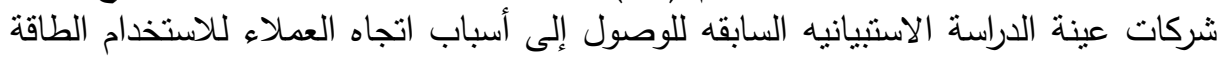

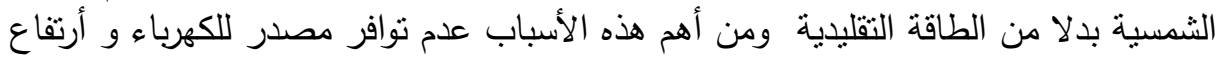

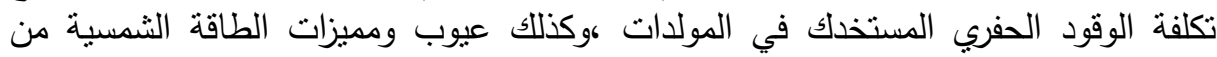

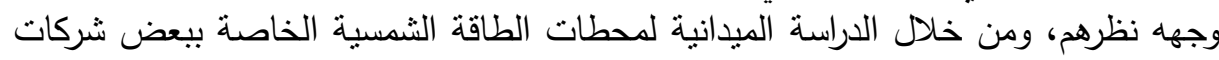

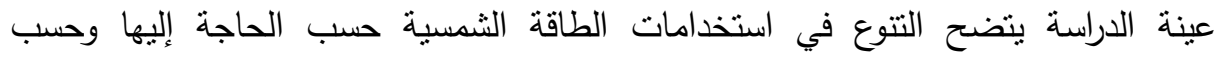

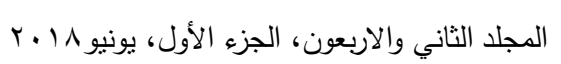




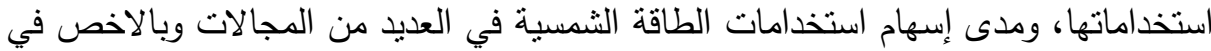

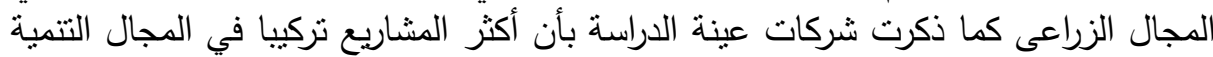

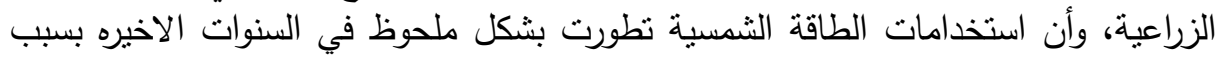

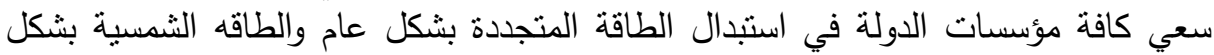

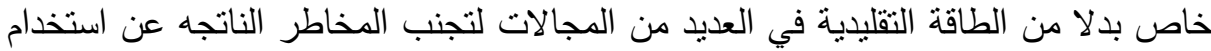

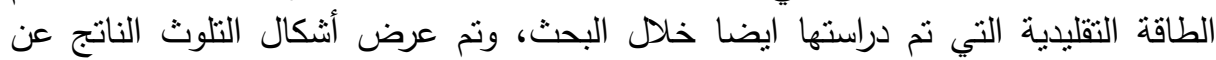

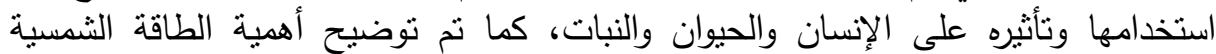

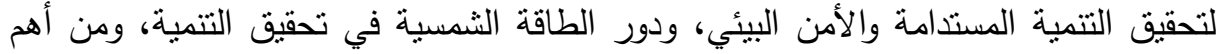

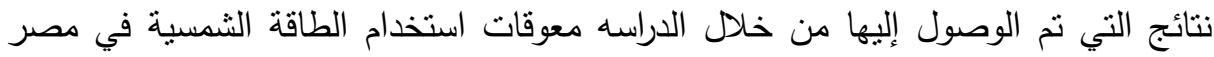

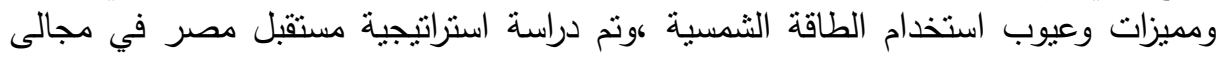
الطاقة المتجدده والبيئة من خلال تشريعات وإليات تتمية الطاقة المتجددة في مصر و و

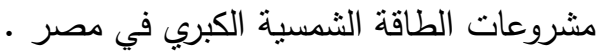

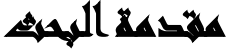

برز خلال عصرنا الحالى، استخدام الطاقة المتجدده وبالأخص الطاقة الشمسية

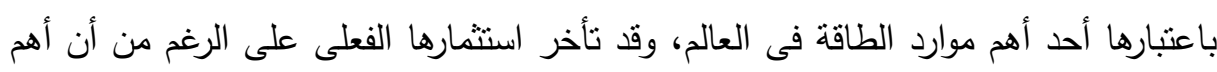

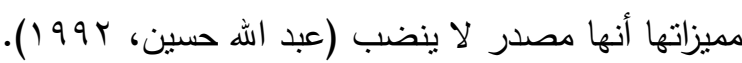
تعد الطاقة الثمسية هى المصدر الرئيسى للطاقة فوق كوكبنا، فالأرض أثنبه بسفينة

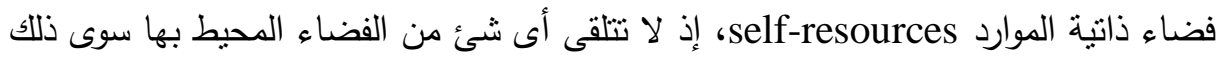
القدر الضئيل جداً الذى بصلها من الطاقة الشمسية والذى يقوم بنسهيل كل عمليات وإليات النظم الأرضية، مثل دورة الغلاف الجوى، وتدوير المياه، وعمليات البناء الضوئى..إلخ لهنيه

$$
\text { (معوض بدوى معوض، تحت الطبع). }
$$

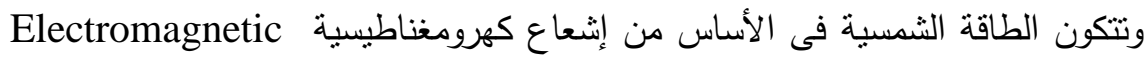
Radiation

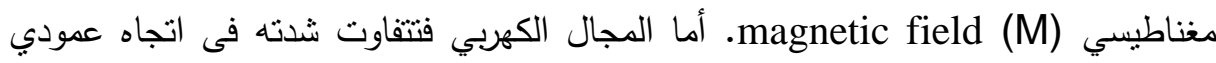

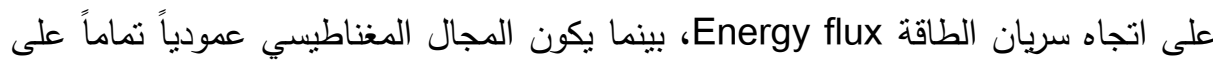
المجال الكهرب، ويتحرك كلا من المجالين (الكهربي والمغناطيسي) بسرعة تساوى لسرعة

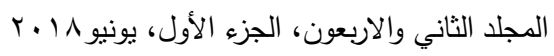


الضوء (C) وتساوى (C) 108 m/s). ويتراوح الطيف الكهرومغناطيسي بصفة عامة بين

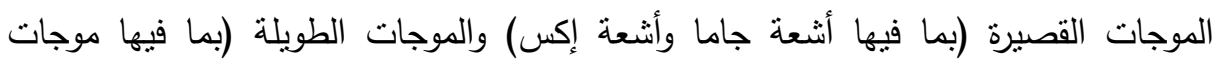

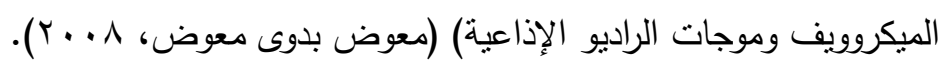

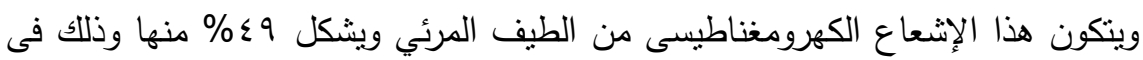

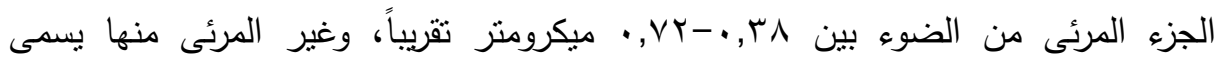

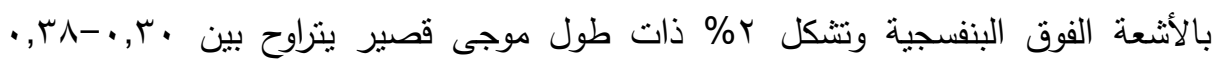

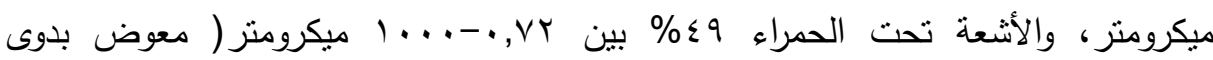

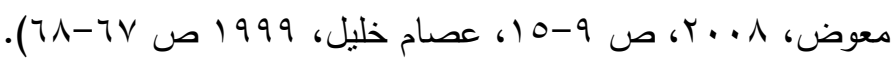
ويثهد العالم منذ أواخر القرن العشرين وبداية القرن الحادي والعشرين تفاقم التحديات البيئية العالمية، وخصوصاً ظاهرة الاحتباس الحراري Global warming، والتغير المناخي، وتآكل طبقة الأوزون، وتلوّث الهواء والمياه العذبة ومياه البحار والمحيطات، وفقدان التراني التنوّع

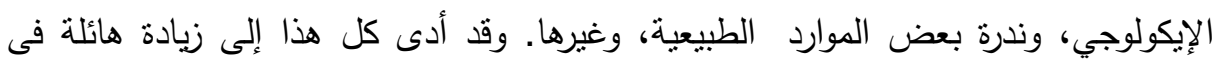

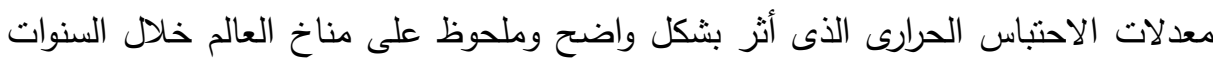

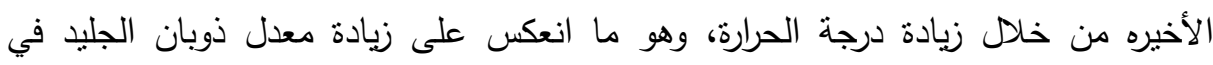

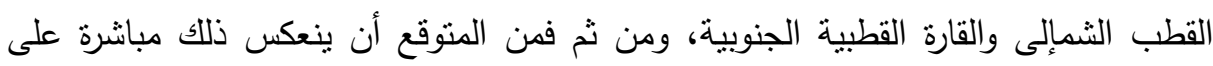

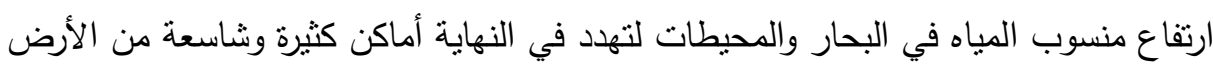
خاصة تلك الأراضى الواطئة مثل دلتا نهر النيل ونهر إلبو فى أسبانيا، على أن ذلك كله يضع عمليات إنتاج الطاقة في أزمة بين الحاجة الملحة إليها والحفاظ على البيئة.

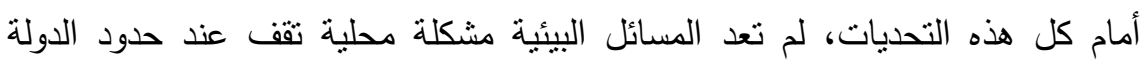
فحسب، بل أصبحت مسألة إقليمية وعالمية. فالمشكلات البيئية أصبحت تطال الإنسان في الدول النامية والدول المتقدمة على حد سواء، وتسهم في تهديد الاستقرار في هذه البلدان. كما

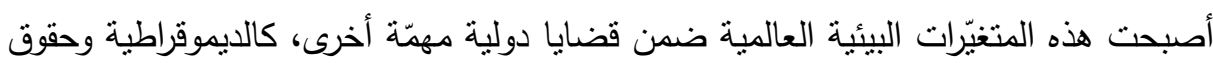
الإنسان والتتمية المستدامة ومكافحة الإرهاب، بل إنها تتصدّر قائمة اهتمامات المجتمع دئه

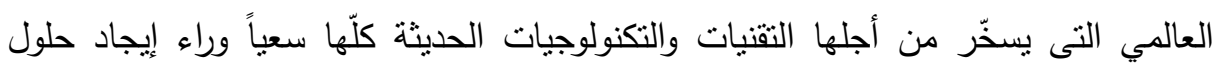

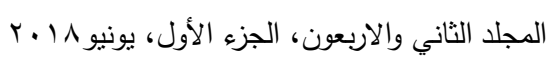


مجدية لها. ومن ثم أنصبت جهود المنظمات الدولية والإقليمية ودول ومنظمات دولية غير حكومية وشركات متعددة الجنسيات من أجل إيجاد خيارات بديلة في مجال الطاقة المتجددة Renewable Energy) ، لتفادي تداعيات الأخطار البيئية، وقد جرى العمل من قبل خبراء البيئة في العالم على إجراء تحسينات في كفاءة الطاقة حول العالم والتحول إلى الموارد المنخفضة الكربون والمتجددة والصديقة للبيئة مثل طاقة الثمس والرياح والمياه والطاقة الحيوية والطاقة الأرضية الحرارية. وقد ساهم التعاون الدولي في صياغة سياسات الطاقة العالمية،

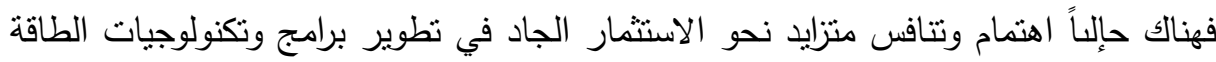

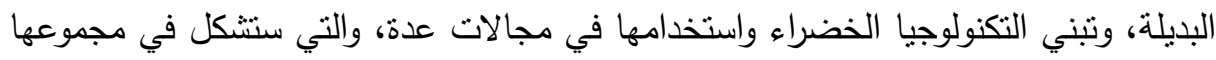
طاقة المستقبل القريب. تعرف الطاقة المتجددة بأنها مصدر للطاقة لا ينضب وقابل للتجديد بسرعة، ويتم

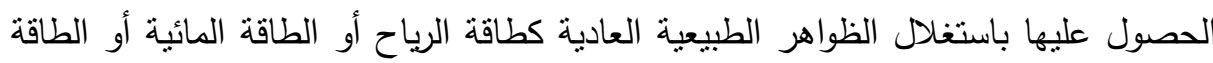

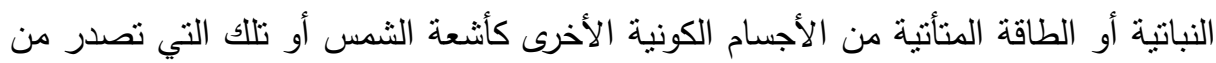
باطن الأرض والمعروفة بالطاقة الجيوحرارية. وتعتبر الطاقة الثمسية إحدى الخيارات الاستراتيجية الرئيسية لتلبية الاحتياجات المستقبلية والمحلية والعالمية من الطاقة حيث إنها تمتاز بتوافرها فى معظم دول العالم، علاوة على كونها طاقة نظيفة غير ملوثة للبيئة ولا تحدث ضوضاء. زد على إنى ذلك بلى بأنها محلية المصدر مما يتلائم مع واقع وأحتياجات تتمية المناطق النائية والريفية وقلة تكإلف الصفيه الصيانة والتتغيل، كما أن التكنولوجيا المستخدمة فيها غير معقدة ويمكن تصنيعها محليا في الدوله النامية. والطاقة الثمسية طاقة متجددة وباقية إلى الأبد بمعنى أنها مصدر مأمون لا يمكن

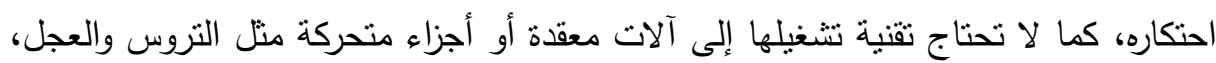

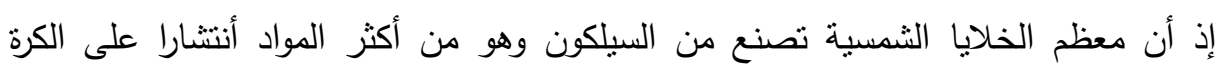
الارضية (حسنى محمد ماهر محمود، 999 ()). 
كما أن استخدام الطاقة الثمسية فى إنتاج الكهرباء في العديد من المناطق النائية والريفية يساعد على تحسين مستوى المعيشة للأفراد، وتوفير احتياجات هذه المناطق من فن فن فئن

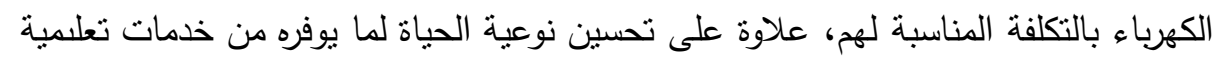

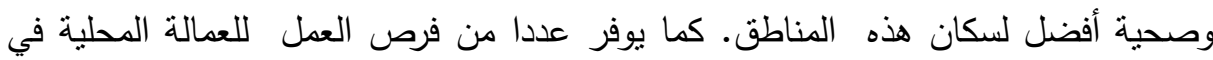
هذه المناطق في مجالات تصنيع وتركيب معدات الطاقة المتجددة وصيانتها، وكذلك محطات إنتاج الكهرباء ومحطات تحليه المياه. يشير التقرير السادس الخاص بتوليد الطاقة الثميّة السادس والصادر في شهر يونيو

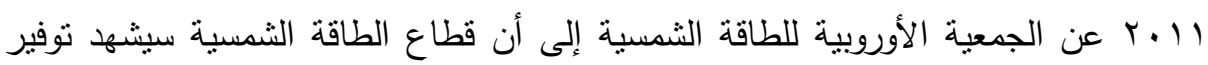

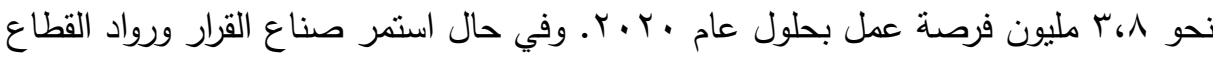

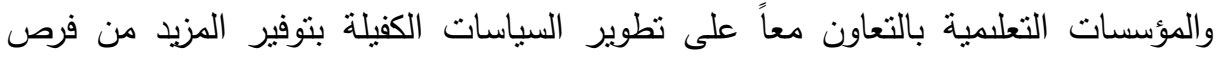

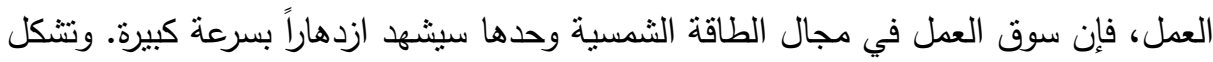

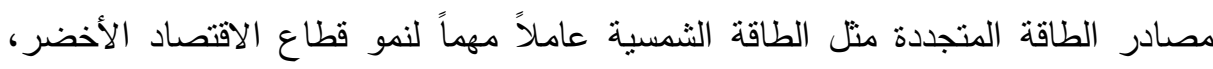
حيث نتير فرص العمل التي يوفرها قطاع الطاقة الثمسية إلى وجود إمكانات كبيرة تساعد

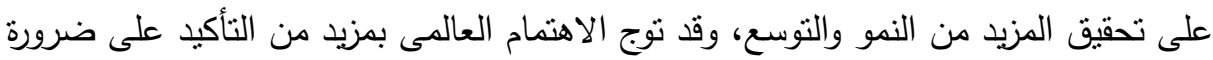
الاعتماد على مصادر الطاقة النظيفة المستدامة باختلاف أنواعها كخيار استراتيجى لتوفير

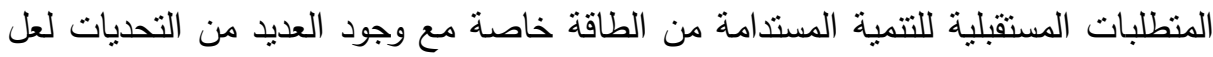
أهمها نضوب مصادر الطاقة التقليدية (الفحم والبترول والغاز الطبيعى) والمتوقع حدوثه بحلول عام •r.r، وكذللك المخاطر الناجمة عن استغلال الطاقة النووية، والارتفاع المتزايد فى معدلات التلوث نتيجة الغازات الدفيئة عن حدود المسموح بها عالميا وعلاقة ذلك بالتغيرات المناخية المترتبة على الإحتباس الحرارى التى من أهم أسبابها استخدام المصادر التقليدية فى

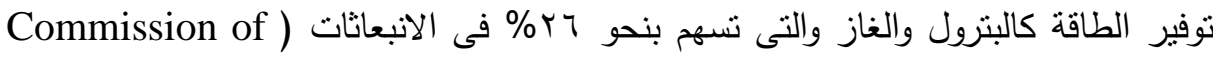

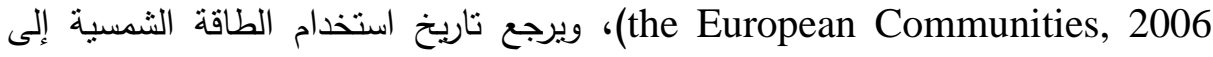
عصر ماقبل التاريخ عندما استخدم الرهبان الاسطح المذهبة لإثعال ميزان المذبح، وفى عام

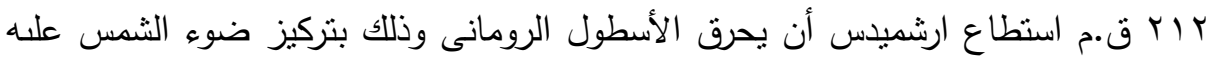

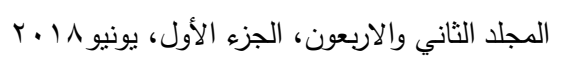


من مسافة بعيدة مستخدما المرايا العاكسة (محمد منير مجاهد واخرون، Y....، ص9؟؟ . $(0$.

تتمثل مشكلة البحث فيما يلي: تحظى الطاقة المتجدده بوجه عام والثمسية منها بوجه خاص اهتماماً على المستوبين العالمى والمحلي. حيث أن على المستوى المحلى فهناك عجز كبلى كبير في الإمداد بالطاقة الكهربائية نتيجة محدودية الامداد بالوقود لمحطات توليد الكهرباء التقليدية الأمر الذي أدى إلى حدوث انقطاعات يومية للكهرباء وخاصة في فصل الصيف، كما يتسم مزيج الطاقة بعدم التوازن أب أنه غير آمن في الوضع الحإلى، حيث يمنل الوقود الأحفوري

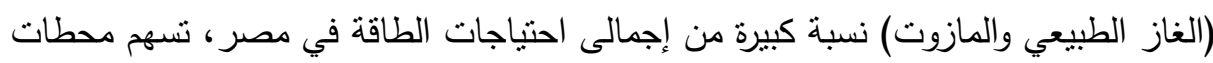
الكهرباء بقدر كبير بملوثات الهواء الاساسية علي المستوي العالمي نظرا للكمبات الكبيره المستخدمة من الوقود الحفري بمحطات توليد الكهرباء من خلال حرق كميات كبيره من (المازوت والغاز الطبيعي والسولار)، يستعمل المازوت في العادة كوقود في محطات نوليد الطاقة الكهربائية، ونتيجة لعمليات حرق الوقود ينتج خليط من الغازات مكونة أساسًا من ثأني فئي

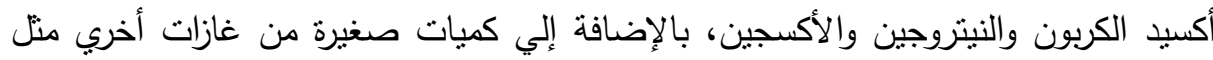

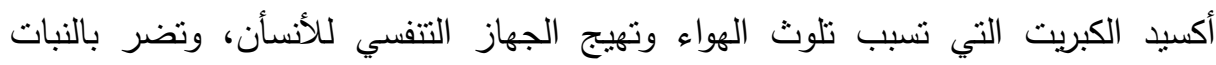
والحيوأن، كما نسبب تآكل المنشآت ويقلل من عمرها الافتراضي( حانم عبد المنعم عبد بهان

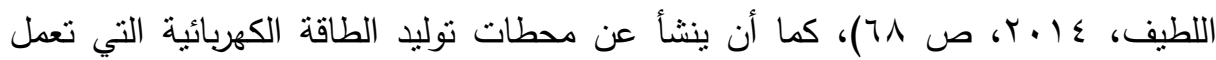
بالديزل العديد من الملوثات أهمها ثأني اوكسيد الكبريت وأكاسيد النتروجين وأول أكسيد الكربون والمواد الصلبة و الهيدروكاربون، وتعتمد كمية أنبعاث ثثائي اوكسيد الكبريت على ولى

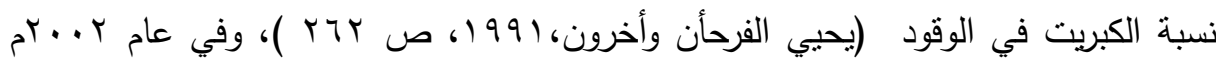

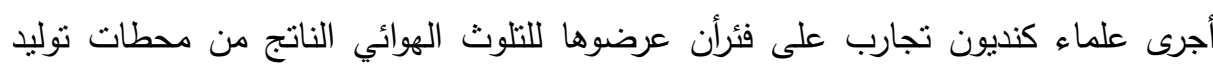

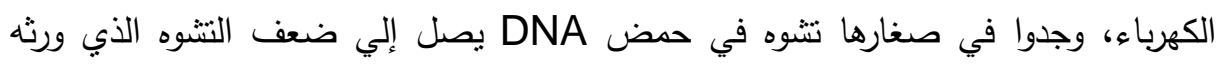

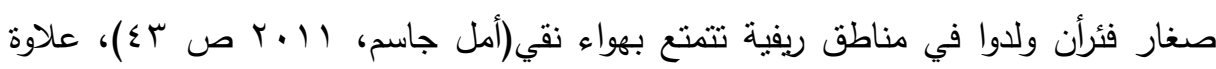

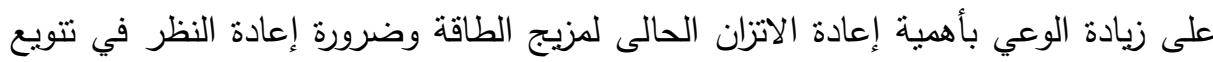

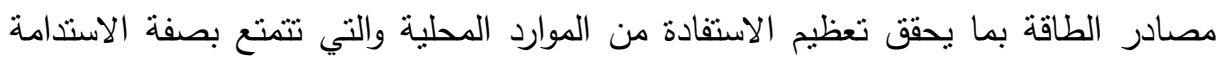


والاستقرار في الأسعار وهي سمات تمثاز بها مشروعات إنتاج الكهرباء من المصادر المتجددة أخذاً في الاعتبار ثراء مصر من هذه الموارد لمواجهة نسبة من الزيادة في الطلب على الطاقة

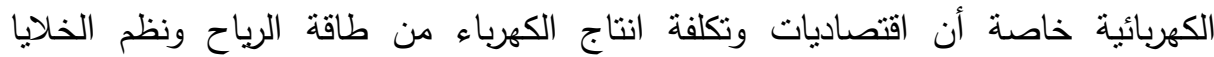
الفوتوفولتية أصبحت منافسة للكهرباء المنتجة من الوقود الأحفوري في حالة عدم تقديم أي

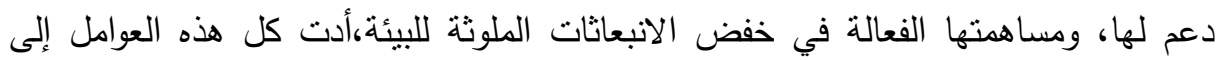
تبني الدولة لاقرار عدة تدابير وتثريعات في زمن قياسي، فيما قد يكون ثورة في التشريعات

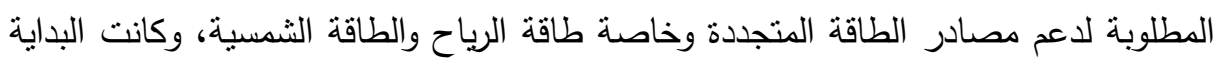

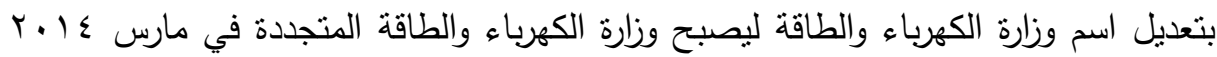

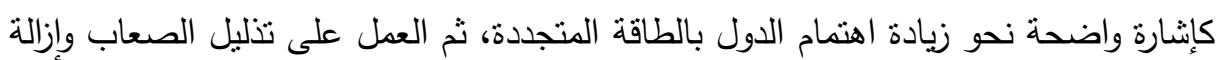
العقبات وتشجيع ودفع الجهود والتخطبط والإعداد وبأفكار وإجراءات غير تقليدية بهدف الإسراع بإنشاء مشروعات بقدرات كبيرة بواسطة القطاع الخاص في غضون ولغون السنوات القليلة القادمة، لتوليد الكهرباء وتوفير الوقود وخفض الإنبعاء ماتثات.

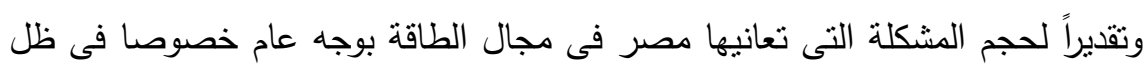

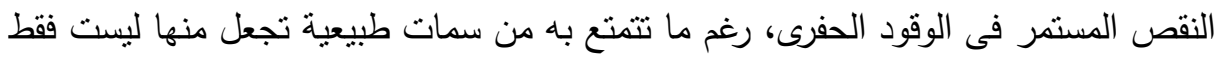

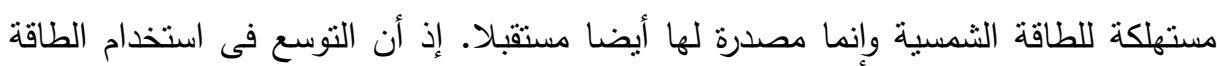

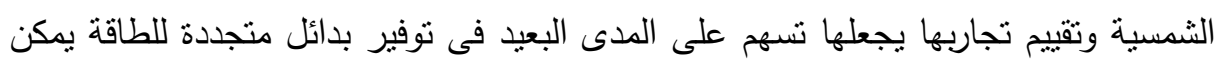
استثمارها فى إدارة المشروعات الصناعية والزراعية وإضاءة المنازل مستقبلا.

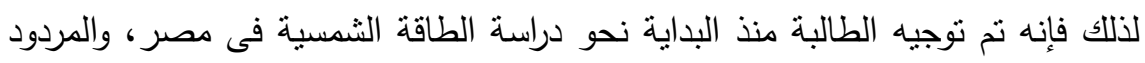
البيئي لاستخدامات الطاقة الثمسية لتقليل كمية الملوثات الناتجة الوقود الاحفورى ومدى تأثنير استخدام الطاقه المتجدده وبالأخص الثمسية فى التتمية المستدامة، ودراسة استخدامات الطاقة الثمسية فى العديد من المجالات. 


\section{اسمئل المهيم}

1 - ما مقدار المتوسط السنوي للإشعاع الثمسي في مصر؟

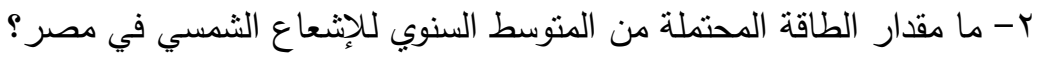
r- ما المعدل الفصلي للإشعاع الثمسي وطاقتة علي مدار فصول السنه في مصر؟

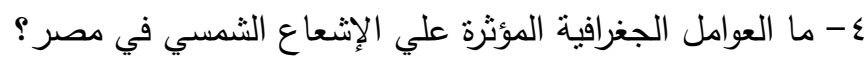

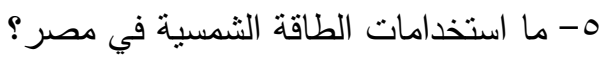

1- ما المعوقات التي تعيق المستثرين الحالين في مجال الطاقة الثمسية وكيفية التغلب عليها؟

V- ما المخاطر استخدام الطاقة التقليدية بمحطات الكهرباء؟ ^- ما دور الطاقة الثمسية في تحقيق التتمية المستدامه والأمن البيئي ؟

9- ما دور الطاقة الثمسية في تحقيق التتمية؟

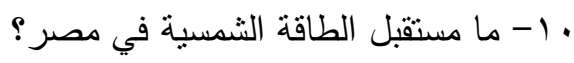

\section{أهساهـ المهنه}

\section{يهذف البحث إلى تحقيق الأهداف التالية:}

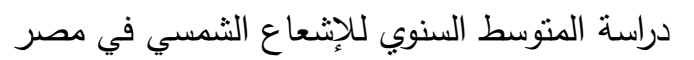

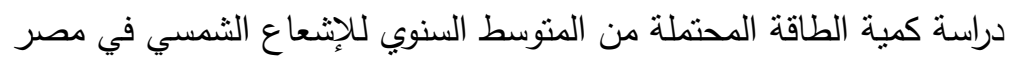

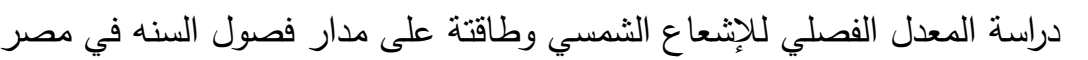
• دراسة العوامل المؤثرة في الطاقة الثمسية دراسة استخدامات الطاقة الثمسية دراسة المشكلات التي تعيق الاستثمار بمجال الطاقة الثمسية في مصر وكيفية التغلب علنها دران دراسة مخاطر استخدام الطاقة التقليدية بمحطات الكهرباء • دراسة دور الطاقة الثمسية في تحقيق التنمية المستدامه والأمن البيئي 


\section{• • دراسة دور الطاقة الثمسية في تحقيق التتمية} • • دراسة مستقبل الطاقة الثمسية في مصر

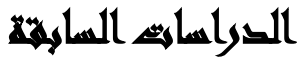

دراسة حسن يونس حسن عبد الرحمن دكتور بقسم الجغرافيا كلية الاداب جامعة طنطا

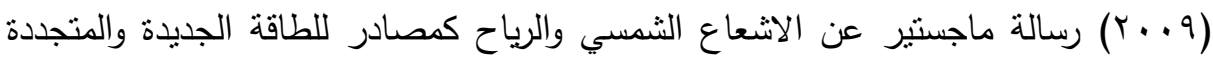

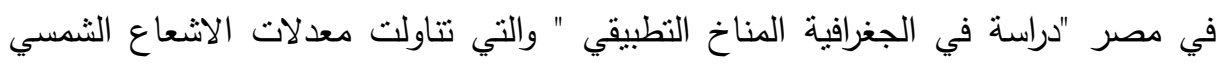
والعوامل المؤثرة عليها ،كما تتاولت عدد من محطات الرصد في مصر وتتاولت دراسة مفصله

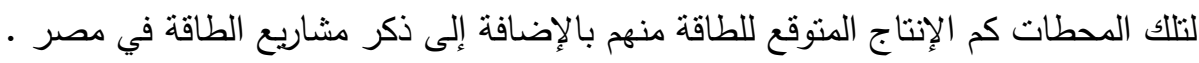
دراسة خالد عبد المجيد محمد عمر (Y Y r Y ) رسالة دكتوراه عن اقتصاديات الطاقة الثمسية في مصر بجامعة عين شمس (دراسة مقارنة ودراسة قياسية ) والتي تتاولت الطاقة الثمسية من الجانب الاقتصادي كما تتاولت جميع مشاريع الطاقة الثمسية في مصر . دراسة خلود حسام حسنين حسن (؟ . . ب) رسالة ماجستير عن اقتصاديات الطاقة الجديدة والمتجددة وإمكانية استثمارها في مصر كلية التجارة جامعة عين شمس قسم الاقتصاد

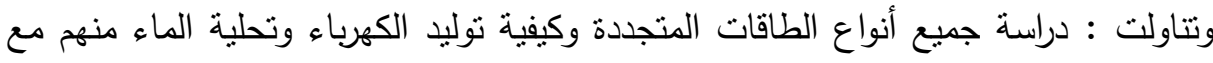

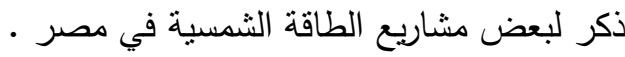

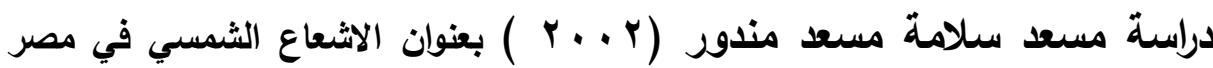
دراسة في الجغرافيا المناخية - رسالة دكتوراه من جامعة المنصورة والتي تتاولت : دراسة الاثعاع الثمسي الكلي في مصر والعوامل المؤثرة فيه وتوزيع الثعاع الثمسي في مصر وذللك خلال شهور السنة بالاضافة إلى نأثثر الاشعاع الثمسي على بعض الجوانب

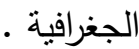

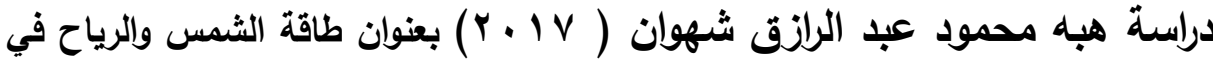
شبه جزيرة سيناء (دراسة في المناخ التطبيقي باستخدام الاستشعار عن بعد ونظم

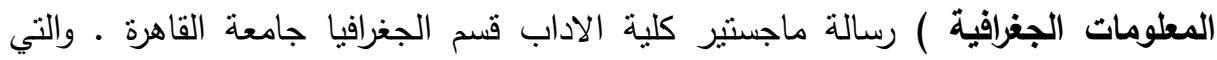

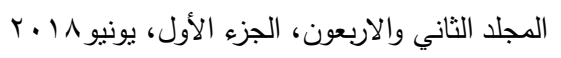


تتاولت طاقة الثمس والعوامل المؤثزه بها وطاقة الرياح في شبه جزيرة سيناء وانسب مواقع لانشاء مشاريع الطاقة الثمسية وطاقة الرياح بشبه جزيرة سيناء .

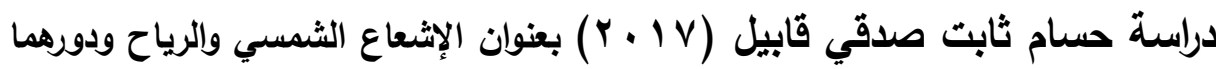
في إنتاج الطاقة في صحراء مصر الثرقية، رسالة ماجستير كلية الاداب قسم الجغرافيا، والتي تتاولت خصائص الإثعاع الثمسي في صحراء مصر الثرقية والعوامل المؤثرة فيها، كما تتاولت مقومات واستخدامات الطاقة الثمسية في صحراء مصر الثرقية ،وخصائص الرياح في صحراء مصر الثرقية ومقومات واستخدامات طاقة الرياح في صحراء مصر الثرقية كما تتاولت على مستقبل الطاقة الثمسية وطاقة الرياح في صحراء مصر الثرقية.

\section{مهاهيمر التوراهة}

الطاقة المتجددة:(Renewable Energy): لبحث حقيقة الطاقة المتجددة لابد من إعطاء مفهوم لها من خلال تعريفها وفقا إلى فرعين نتتاول في الفرع الأول : تعريف الطاقة المتجددة كما ذكر المختصين الفرع الثاني: تعريف الطاقة المتجددة وفق الهيئات الدولية

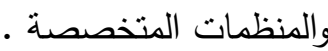
الفرع الأول: تعريف الطاقة المتجددة كما ذكر المختصين: فقد عرفها البعض على أنها

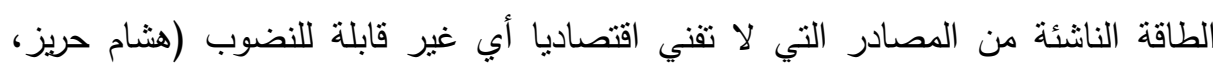

$$
\text { (). (1) }
$$

وقد عرفت أيضا بأنها المصادر الأولية الموجودة في الطبيعة ومتوافرة باستمرار وتتشمل

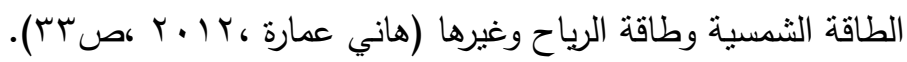

وكذلك عرفت الطاقة هي إحدى المقومات الرئيسية للمجتمعات المتحضرة، وتحتاج إلدها

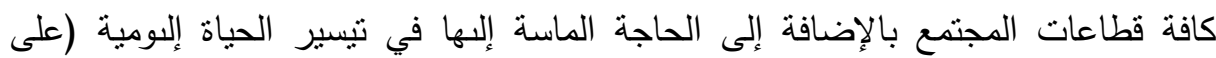

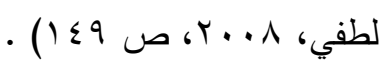


الفرع الثاني: تعريف الطاقة المتجددة وفق الهيئات الدولية والمنظمات المتخصصة: تتاولت الطاقة مختلف الهيئات الدولية والمنظمات المتخصصة في مجال حماية البيئة في عدة تعريفات حيث عرفتها وكالة الطاقة العالمية بان الطاقة المتجددة تتتكل من مصادر الطاقة الناتجة من مسارات الطبيعة التلقائية كأشعة الثمس والرياح، والتي تتجدد في الطبيعة بوتيرة

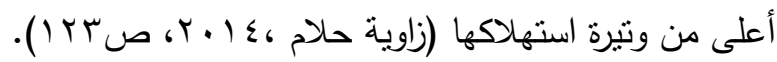
الطاقة غير المتجددة ( Non-Renewable Energy)هي الطاقة القابلة للنفاذ والتي تكونت في طبقات الأرض منذ ملايين السنين ولها مخزون محدد سينتهي باستهلاكه ،وتخخل

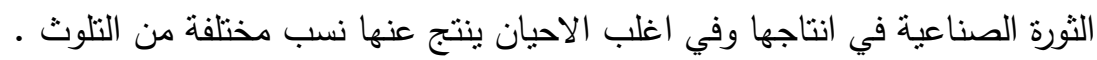
الحدود البيئية: وهي أن لكل نظام طبيعي حدودا معينة لا يمكن تجاوزها في الاستهلاك والاسنتزاف وأن تجاوز هذه القدرة يعني تدهور النظام الطبيعي واختلاف توازنه ( باتر محمد لند

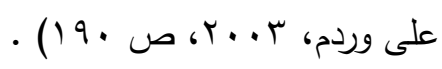
التنمية المستدامة: يعود أصل مصطلح الاستدامه Sustainable إلى علم الايكولوجيا Ecology عرضة - نتيجة ديناميكيتها - إلى تغيرات هيكلية تؤدي إلى حدوث تغير في خصائصها

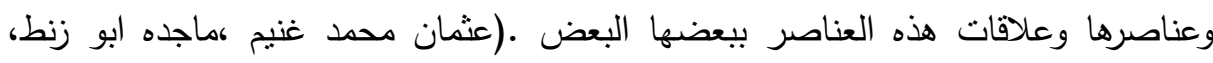

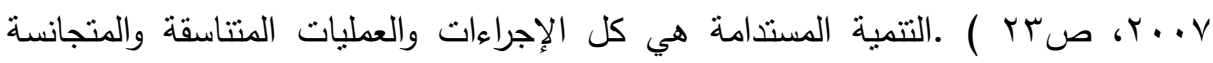
اللازمة لتغيير استغلال الموارد كتوجيه الاستثمارات كتوجهات التتمية التكنولوجية ،والتغيرات التهية المؤسسية ،بما يضمن إثباع الحاجات والأنشطة الإنسانية الحالية والمحتملة مستقبلا .

(Beat,B, 2000, P 44.)

الأمن البيئي: هو أقصي حماية للبيئة بكافة جوانبها في البر والبحر والهواء ومنع أي تعد

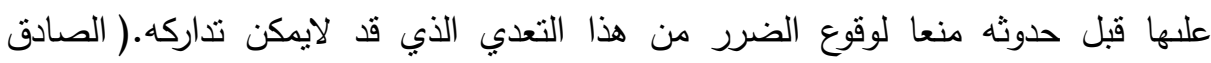

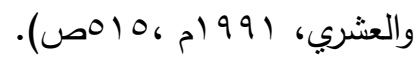


الاشعاع الشمسي المباشر :Direct Normal Irradiance (DNI): هو الاشعاع المستقبل مباشرة من قرص الثمس على سطح متعامد مع الاشعة (نعمان شحادة ،9. . . . ( 19 ص

الخلايا الشمسية PV: هي عبارة عن ألواح مصنوعة من الزجاج النقي جدا أو المرايا العاكسة للضوء حيث وظيفتها تختلف عن المجمعات الثمسية في أنها تعمل بواسطة الضوء وليست الحرارة حيث نقوم بتحويل الضوء إلى كهرباء.(المنظمة العربية للثقافة والعلوم -

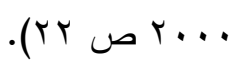

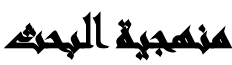

تم الاعتماد على المنهج الوصفي التحليلى من خلال وصف الجوانب المتعلقة بموضوع

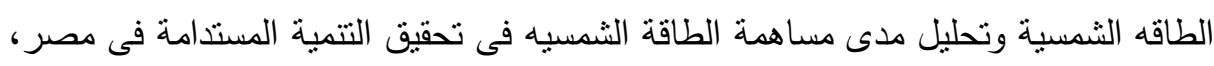

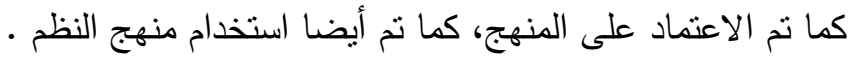

\section{أسوايت التصراسة}

\section{البيانات الاحصائية:}

- البيانات المناخية ممنلة فى الاشعاع الثمسي و الحرارة وعدد ساعات السطوع الثمسى وكمية السحب وكمية الطاقة المحتمله من الاشعاع الثمسي المباثر .

- بيانات عن ملوثات الغلاف الجوى الناتجة عن استخدام الوقود الحفرى فى انتاج الطاقة الكهربائية، والمتعلقة كذلك بحركة المركبات فى بعض الطرق الرئيسية. بيانات الاراسة الميدانية والاستقصاء الميدانى: البيانات الأولية: وذلك بالبحث في الجانب الميداني بتوزيع استبيانات لدراسة بعض مفردات

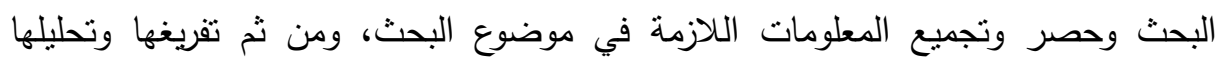

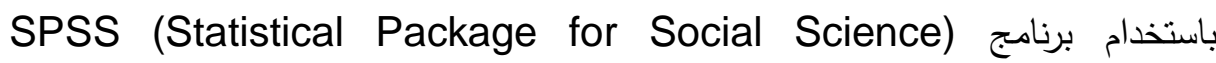


الإحصائي واستخدام الاختبارات الإحصائية المناسبة بهدف الوصول لدلالات ذات قيمة ومؤشرات تدعم موضوع الدراسة.

البيانات الثانوية: وقد قامت الباحثة بمراجعة الكتب والدوريات والمنشورات الخاصة أو المتعلقة

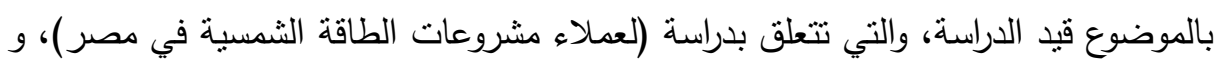

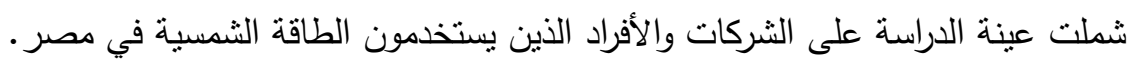
شملت عينة البحث على : •r شركة من الشركات العاملة في مجال الطاقة الثمسية،

r r فرد من مستخدمين الطاقة الثمسية.

أداة الاستبيان: نم بناء أداة (استبيان) خاصة للتعرف على عملاء مشروعات الطاقة الشمسية في مصر مان وستتكون أداة الارلسة من:

الأداة الأولهى: نم تصميمها وتوزيعها على الثركات العاملة في مجال الطاقة الثمسية. الأداة الثانبة: نم تصميمها وتوزيعها على الأفراد.

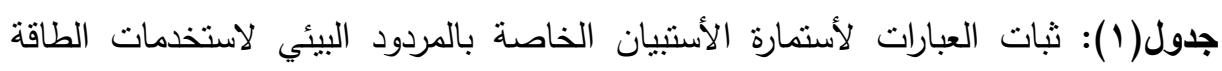

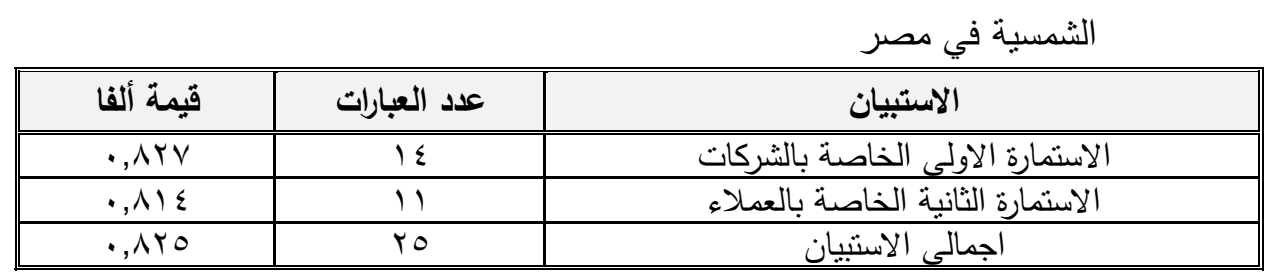
يتضح من الجدول السابق أن قيم معاملات الثبات لأبعاد مقياس بالمردود البيئي

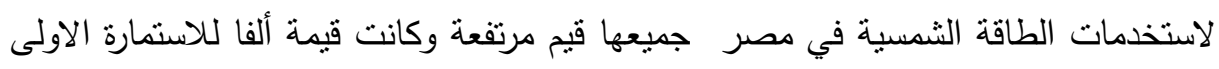

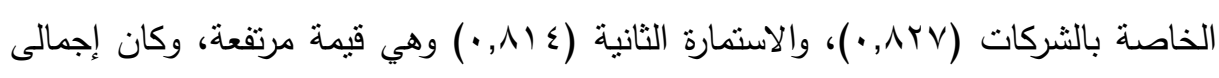
المقياس بقسمة (AYO, •) وتتشير هذه القيم من معاملات الثبات إلى صلاحية العبارات وإمكانية الاعتماد على نتائجها والوثوق بها. 
جدول(ץ): صدق الاتساق الداخلي لأستمارة الأستبيان الخاصة بالمردود البيئي لاستخدمات الطاقة الثمسية في مصر

\begin{tabular}{|c|c|c|}
\hline إجمالي المقياس & مسية في مصر & المردود البيئي لاستخدمات \\
\hline$(* *) \cdot, \vee Y q$ & معامل ارتباط بيرسون & \multirow{2}{*}{ الاستمارة الاولى الخاصة بالشركات } \\
\hline$\cdot, \cdots 1$ & الدلالة المعنوبة & \\
\hline$(* *) \cdot, 794$ & معامل ارتباط بيرسون & \multirow{2}{*}{ الاستمارة الثانية الخاصة بالعملاء } \\
\hline$\cdot, \cdots 1$ & الدلالة المعنوية & \\
\hline$(* *) \cdot, \vee \wedge 0$ & معامل ارتباط بيرسون & \multirow{2}{*}{ اجمالى الاستبيان } \\
\hline$\cdot, \cdots 1$ & الالالة المعنوية & \\
\hline
\end{tabular}

من جدول صدق الاتساق الداخلي السابق لأبعاد مقياس لأستمارة الأستبيان الخاصة بالمردود البيئي لاستخدمات الطاقة الشمسية في مصر نجد أن معامل الارتباط الاستمارة الاولى الخاصة بالثركات والاستمارة الثانية الخاصة بالعملاء وإجمالي المقياس دالة معنوياً عند مستوى معنوية (0. . •))، مما يؤكد على صدق الاتساق الداخلي لأبعاد المقياس .

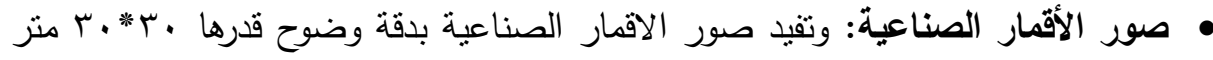
فى عمل خرائط للغطاءات الأرضية وتصنيف مظاهر السطح. كما تقيد نماذج الارتفاعات الرقمية فى دراسة أثنكال السطح الرئيسية وعلاقتها بالمشروعات المقامة ودراسة درجات الانحدار.

وتعتمد دراسة الإشعاع الثمسى فى مصر على البيانات الخاصة بمنوسط الإشعاع

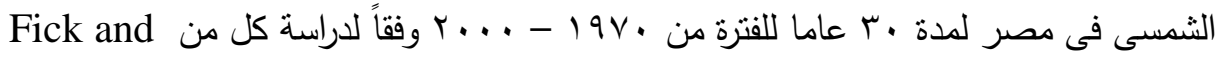

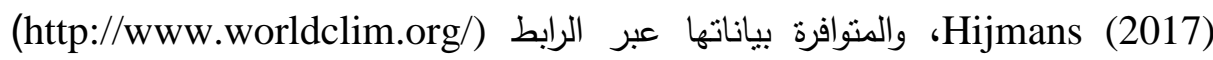

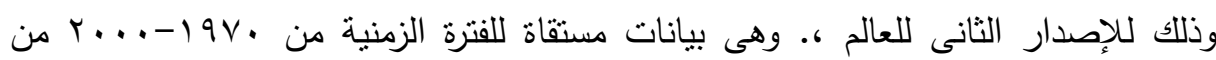

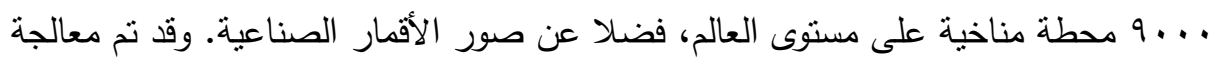
هذه البيانات مجتمعة وعمل استتباط باستخدام اداة التحليل المكانى Spline بالاعتماد كذلك

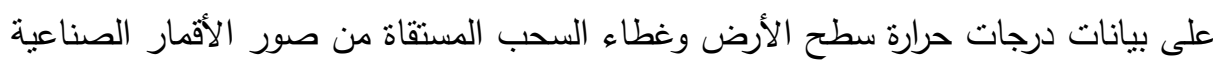

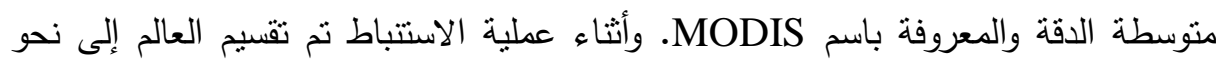
Tr إقليم استتادا على كثافة المحطات المناخية فى كل منها، واستعملت بيانات القمر

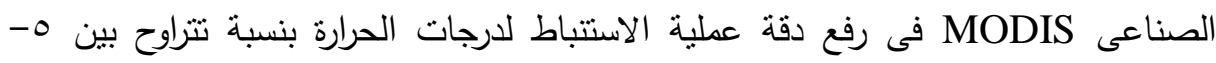
236

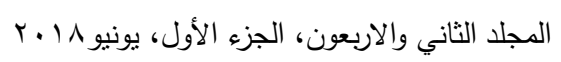




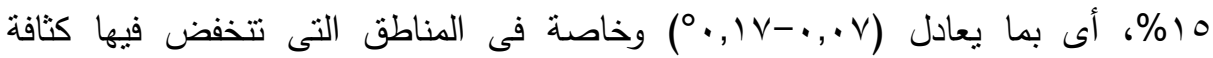

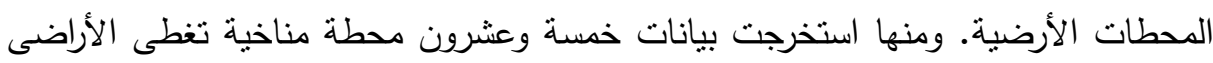

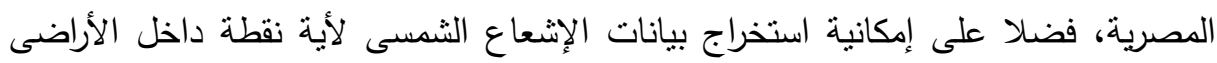

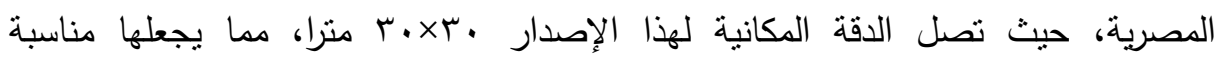
لأغراض الدراسة الحالِلة.

• حزم برامج نظم المعلومات الجغرافية: وتفيد مجموعة برامج نظم المعلومات الجغرافية وعلى رأسها برناج ARCGIS فى إدخال البيانات المكانية، وعمل قاعدة بيانات مكانية شاملة يتصل فيها كل من البيانات الوصفية والإحصائية بالبيانات المكانية (الخرائط

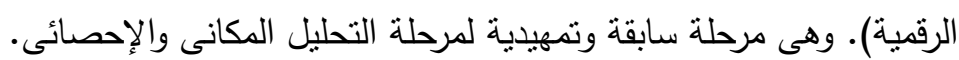
وهذه قائمه بأهم البرامج المستخدمة في الرسالة: Arc Gis10 بيانات جغرافية وإخراجها كخرائط حامله البيانات التي قامت الطالبة بجمعها.

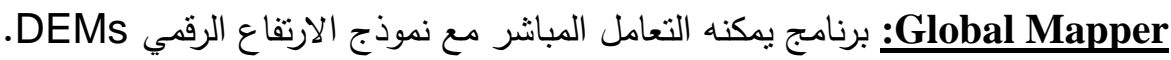
.Google earth

\section{And}

تتمثل حدود البحث في الآتي: • الحدود المكانية: ويمثله الحيز المكانى أو الجغرافى الذى تشغله جمهورية مصر العربية.

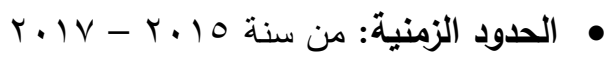

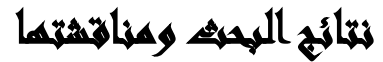

يمكنا القول بأن مصر تقع فيما يعرف بنطاق الحزام الثمسى، مع أيام تغيم بشكل

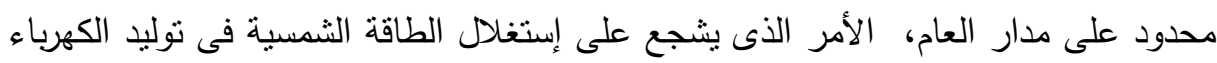

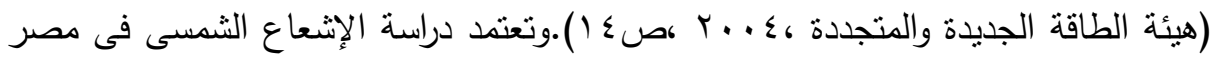

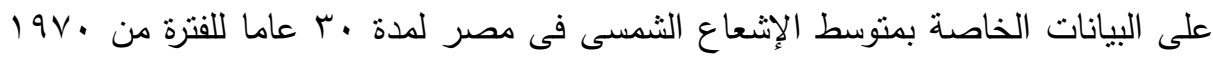

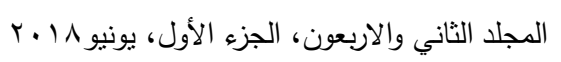


- . . . Fick and Hijmans (2017) وفقا لدراسة كل من والمتوافرة بياناتها عبر الرابط (http://www.worldclim.org/)

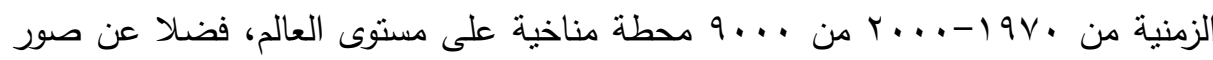
الأقمار الصناعية. وقدم تم معالجة هذه البيانات مجتمعة وعمل استتباط باستخدام اداة التحليل

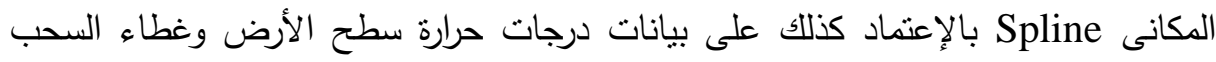
المستقاة من صور الأقمار الصناعية متوسطة الدقة والمعروفة بأسم MODIS. الإسنتباط نم تقسيم العالم إلى نحو بr إقليم استتادا على كثافة المحطات المناخية فى كل منها، واستعملت بيانات القمر الصناعى MODIS فى رفع دقة عملية الاستتباط لدرجات

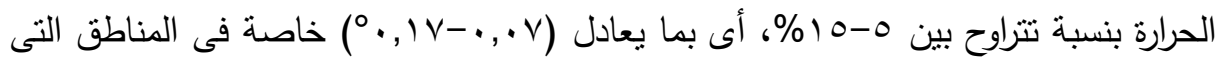
تتخفض فيها كثافة المحطات الأرضية. ومنها استخرجت بيانات خمسة وعشرون محطة بنة

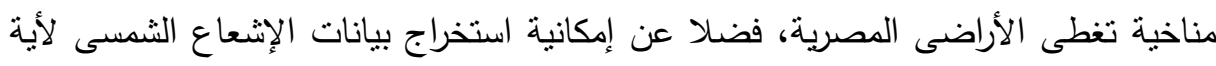

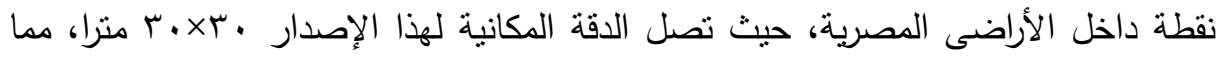

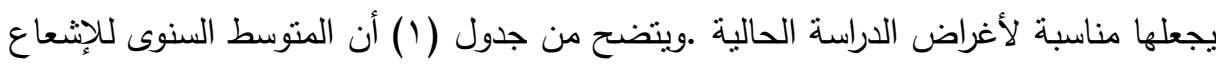

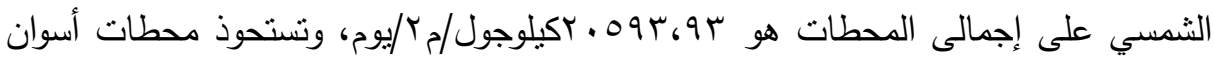

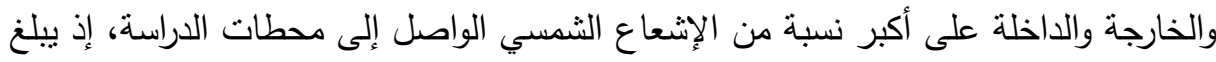

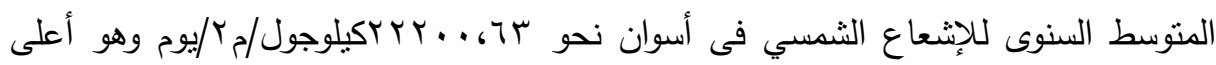
معدل سنوى للإثعاع الثمسي فى مصر، بينما نسجل المحطات الساحلية ممثلة فى مرسي

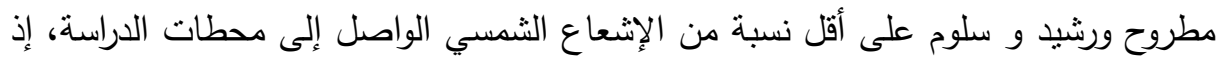

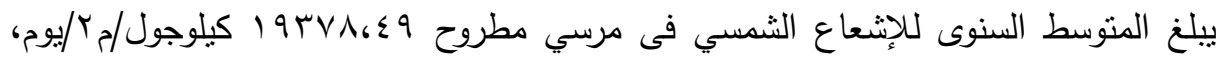

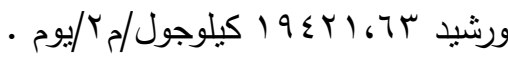


عبد العزيز عبد اللطيف وآخرون

جدول(r): المتوسط السنوى للإشعاع الثمسي المباشر فى مصر (كيلوجول/مج//يوم).

\begin{tabular}{|c|c|c|c|c|c|c|c|}
\hline المتوسط & $Y$ & $x$ & المحطة & المتوسط السنوي & $\mathbf{Y}$ & $\mathbf{x}$ & المحطة \\
\hline 21567 & 27.1807 & 31.1826 & اسيوط & 19668.4 & 31.127 & 33.8004 & العريش ل ل الع \\
\hline 21229.3 & 28.0985 & 30.7984 & المنيا & 19637.5 & 31.265 & 32.2995 & بورسعيد \\
\hline 21311 & 28.541 & 28.9779 & الواحات & 20366.6 & 29.597 & 32.7 & رل راس سدر \\
\hline 20588.6 & 29.2011 & 25.5163 & سيوة & 19955.1 & 30.618 & 32.2899 & الاسماعيلية \\
\hline 19533.9 & 31.5671 & 25.1601 & السلوم & 19421.6 & 31.443 & 30.4264 & رشيد \\
\hline 22026.5 & 25.4448 & 30.5485 & الخارجة & 19692 & 30.868 & 29.6322 & الاسكندرية \\
\hline 22020.4 & 25.6372 & 29.0051 & الداخلة & 19859.5 & 30.830 & 28.9506 & العلمين \\
\hline 21657.5 & 27.2137 & 28.1705 & الفرافرة & 19378.5 & 31.353 & 27.2546 & مرسى مطروح \\
\hline 20051.7 & 29.9093 & 33.7505 & نذل & 20498.6 & 28.112 & 33.8145 & طور سيناء \\
\hline 20518.5 & 28.7525 & 33.3301 & ابورديس & 20802.6 & 27.243 & 33.8366 & الغردقة \\
\hline 20259.4 & 29.8459 & 31.3292 & حلوان & 20803 & 26.112 & 34.2768 & القصبر \\
\hline 20006.1 & 29.0394 & 34.6612 & نوييع ل ن ل & 22200.6 & 24.090 & 32.9085 & اسوان \\
\hline 20593,9 & - & - & مج & 21794.5 & 25.698 & 32.6444 & الاقصر \\
\hline
\end{tabular}

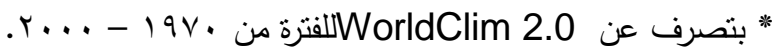

ويشير شكل (1) الخاص بالتوزيع المكانى للإثعاع الثمسى فوق الأراضى المصرية

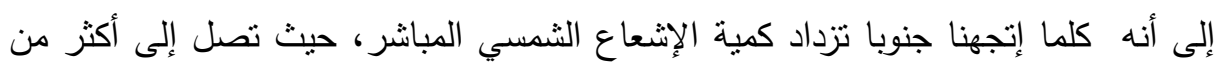

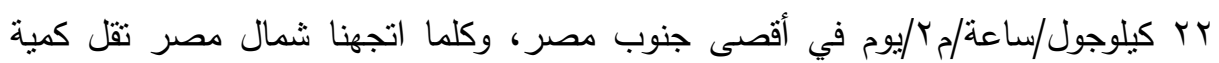

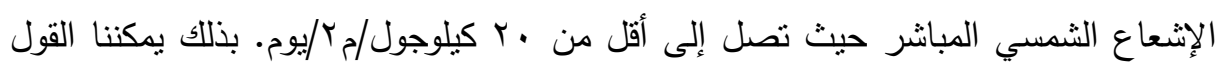

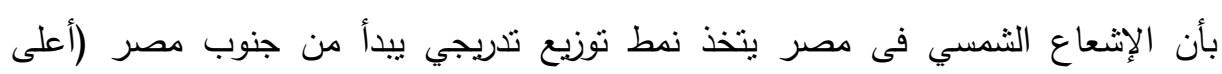
المعدلات) وينتهى شمال مصر (أقل المعدلات). 


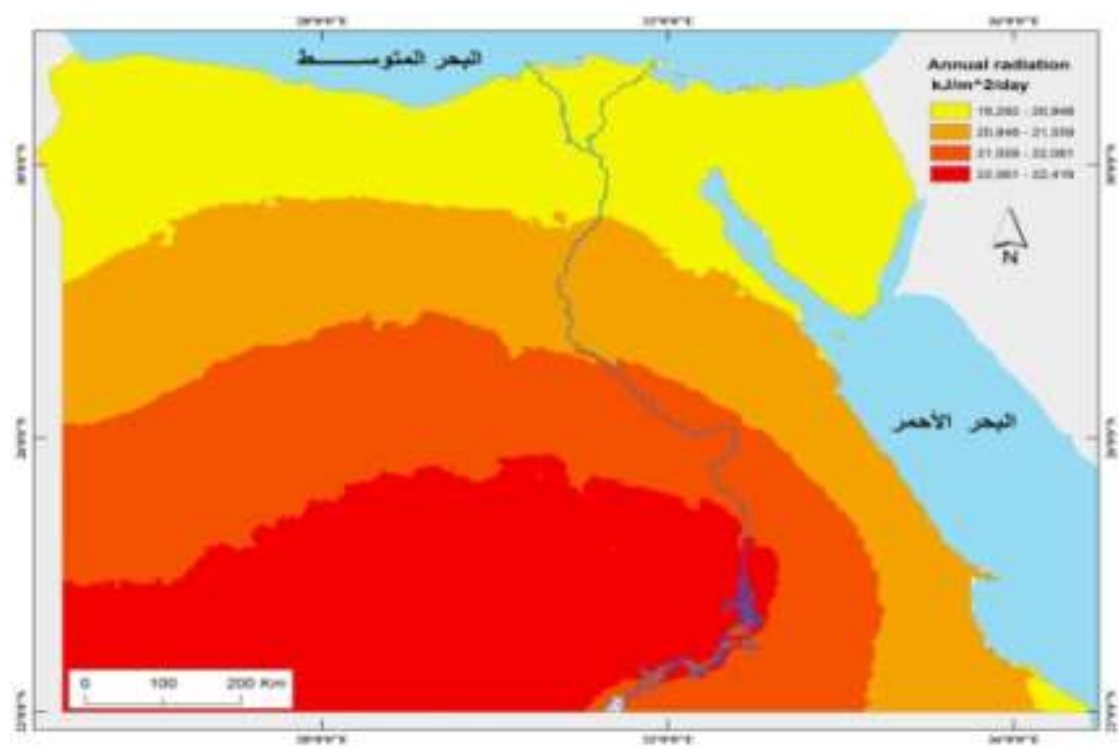

شكل(1): المتوسط السنوى للإثعاع الثمسي في مصر (كيلوجول/مَ//يوم).

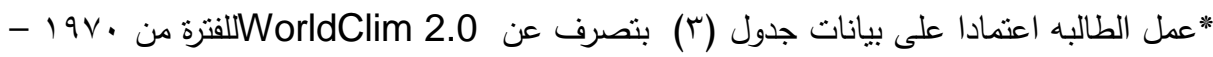
. . . .

كمية الطاقة المحتملة من الإثعاع الثمسى المباشر: يمكن حساب كمية الطاقة المنوقعة أو

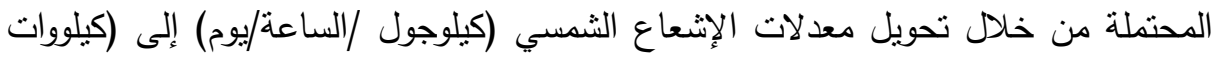

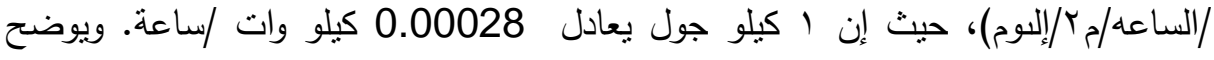
جدول رقم (ع) أن المتوسط السنوي لكمية الطاقة المحتملة من الإشعاع الثمسي المبانش في

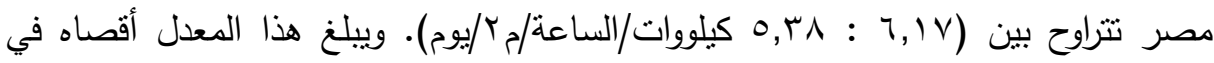

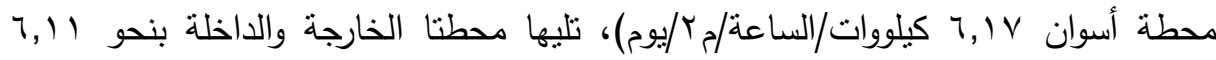

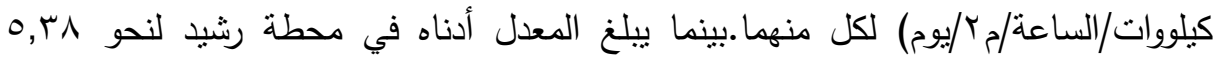

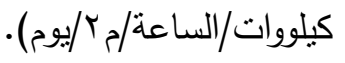




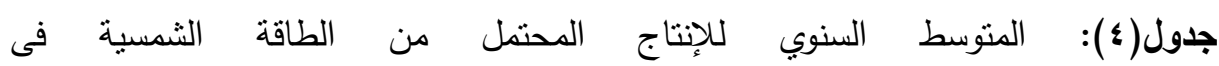

\begin{tabular}{|c|c|c|c|}
\hline & \multicolumn{3}{|c|}{ مصر (كيلووات/الساعة/r/Y يوم). } \\
\hline للإنتاج المحتمل المنوي & المحطة & المتوسط السنوى للإنتاج المحتمل & المحطة \\
\hline 5.99 & اسيوط & 5.46 & العريش \\
\hline 5.89 & المنيا & 5.45 & بورسعيد \\
\hline 5.92 & الواحات البحرية & 5.66 & راس سدر \\
\hline 5.70 & سيوة & 5.55 & الاسماعيلية \\
\hline 5.43 & السلوم & 5.38 & رشيد \\
\hline 6.11 & الخارجة & 5.45 & الاسكندرية \\
\hline 6.11 & الداخلة & 5.51 & العلمبين \\
\hline 6.02 & الفرافرة & 5.35 & مرسى مطروح \\
\hline 5.57 & نخل & 5.69 & طور سيناء \\
\hline 5.70 & ابورديس & 5.78 & الغردقة \\
\hline 5.62 & حلوان & 5.85 & القصير \\
\hline 5.56 & نويبع & 6.17 & اسووان \\
\hline 0,119 & متوسط عام & 6.06 & الاقصر \\
\hline
\end{tabular}

* من حساب الطالبة اعتمادا على بيانات جدول ه.!

وبالنسبة لنتائج الاستبيان الخاص بالثركات عن مقترحاتهم لإنتشار تكنولوجيا الطاقة

الثمسية في المستقبل؟

يوضح جدول رقم(ه): إجابات عينة الدراسة على السؤال الثالث عثر

\begin{tabular}{|c|c|c|}
\hline العدد & العبارات & s \\
\hline 1 & التوعية - التصنيع المحلى بجودة عالية. & 1 \\
\hline T & انتتار الوعى الخاص بالحفاظ على البيئة وترشيد الاستهلالك. & r \\
\hline 1 & انخفاض الفائدة البنكية، التمويل. & r \\
\hline$T$ & تخفيض الجمارك / التصنيع المحلى. & $\varepsilon$ \\
\hline 1 & تقليل استهلاك الكهرباء. & 0 \\
\hline 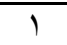 & زيادة تعريفة الكهرباء & 7 \\
\hline 1 & وضع شروط للأجهزة والادوات المستخدمة لضمان جودة عالية للمستهلكين & $\mathrm{V}$ \\
\hline $\mathrm{V}$ & الإجمالى & \\
\hline
\end{tabular}

يتضح من الجدول (0) أن V فقط من اجمالي عينة الدراسة هم من قدموا مقترحات

تتعلق بالإجابة عن السؤال الثاني عشر من لان

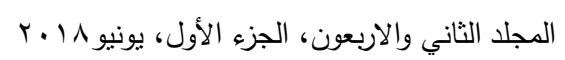


التوعية والتصنيع المحلي بجودة عالية كانت احدي المقترحات لانتشار تكنولوجيا الطاقة الثمسية في مصر فالتوعيه باهمية الطاقة الثمسية و وكيفية استخدامها وأهية استخدامها للحفاظ علي البيئة تحقيق التتمية المستدامه مقترح هام لانتشار الطاقة الثمسية في المستقبل وايضا التصنيع المحلي لتوفير المنتجات بسعر منخفض مما يعمل علي نتشيط الاستثمار

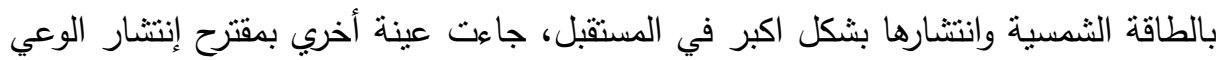
الخاص بالحفاظ على البيئة وترشيد الاستهلاك وهذا المقترح شبيه لما قبلها أي ان العمل علي الئي

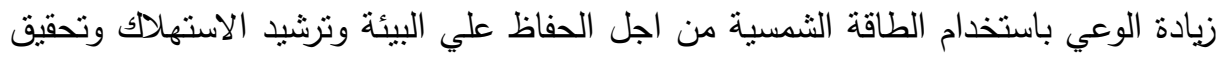

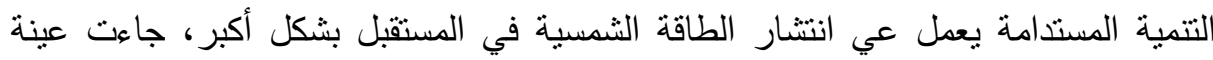
اخري من عينة الدراسة بمقترح انخفاض الفائدة البنكية والتمويل وهذا مايوضح ضرورة التسهيلات البنكية لانتشار الطاقة الثمسية في المستقبل، وعينة اخري ذكرت أن تخفيض الجمارك والتصنيع المحلي من المقترحات الهامة لانتثار الطاقة المشسية في المستقبل لان تخفيض الجمارك والتصنيع المحلي يخفض من سعر تكنولوجيا الطاقة المشسية في مصر

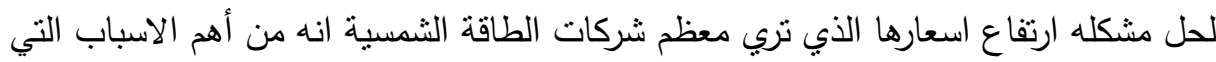

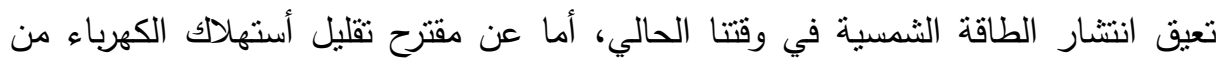
عينة الدراسة يعني ان كلما زاد توعية افراد المجتمع بضروره ترشيد استهلاك الكهرباء كلما

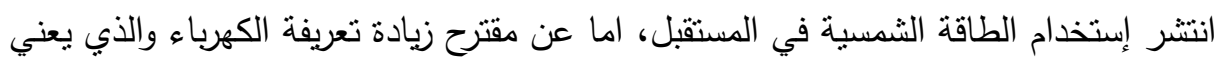
زيادة سعر شراء الكهرباء لتحقيق هامش ربح للمستثرين وللنتجيع الاستثمارات وبخاصة أمام فئي المشروعات الصغيرة والمتوسطة فى مجال الطاقة التى تعتبر قاطرة التتمية فى الدول المتقدمة

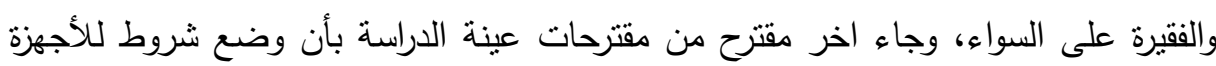
والادوات المستخدمة لضمان جودة عالية للمستهلكين يضمن كفاءة الطاقة الثمسية وزيادة نقة العملاء بها مما يعمل علي انتشارها بشكل اسرع في المستقبل . 


\section{اللزوسيان}

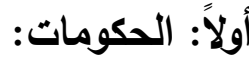

1- وضع خطة مستقبلية لتشجيع وزيادة التصنيع المحلي لتقنيات الطاقة الثمسية مع رفع كفائتها وتطويرها بهدف خلق سوق محلي ينافس السوق العالمي. r- خفض التكلفة الأولية لمحطات الطاقة الثمسية من خلال السياسات الضريبية المناسبة

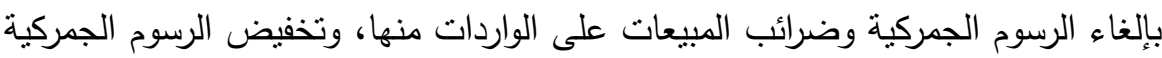

$$
\text { على مستلزماتها في المستقبل. }
$$

r- رفع سعر تعريفة شراء الطاقة الكهربائية المنتجة من خلال محطات الطاقة الثمسية. ع- نشر التوعية باستخدامات الطاقة الثمسية في جميع المجالات عن طريق وضع خطط

$$
\text { دعائية في جميع الوسائل الأعلانية المقروء منها والمسموع. }
$$

0- تخصيص نسبة من ميزانية الدولة لدعم الابحاث المتخصصة في علوم ومجالات الطاقة

\section{ثانياً: مؤسسات التمويل:}

1 - وضع برتوكول تعاون بين جهات الدولة المختصة والبنوك لتسهيل خطط التمويل

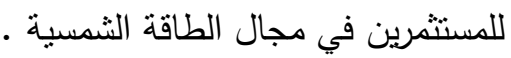

r- توجيه بورصة الأوراق المالبة للمدخرات والاستثمارات في مجال الطاقة الشمسية ،وذلك

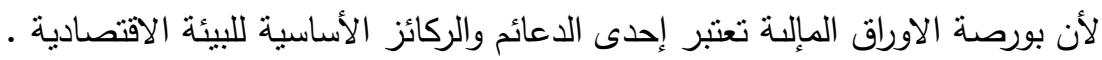

\section{ثالثاً: مؤسسات المجتمع المدني:}

1 - مشاركة الجمعيات الأهلية في التوعية المجتمعية لضرورة استخدام الطاقة الثمسية .

r r عمل ندوات بصفة دورية للتوعية عن أهمية الطاقة الثمسية .

رابعاً: المؤسسات التعليمية ومراكز البحث والتطوير :

1 - توجية جهود المراكز والمؤسسات البحثية والعلمية المحلية لتطويرتكنولوجيا الطاقة .

r - إنشاء قسم لتكنولوجيا الطاقة المتجددة بالدارس والمعاهد.

r - إنشاء مراكز تدريب لتدريب الفنين بمجال الطاقة الثمسية.

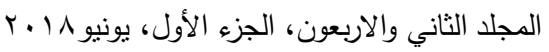




\section{خامساً: شركات الطاقة:}

1- الالتزام باسعار المنتجات المحلية .

r- تحقيق أعمال الصيانة اللازمة خلال فترة الضمان لتحقيق نقة العملاء بأنظمة الطاقة الثمسية.

r- وضع خطط تسويقية ذات رؤية مستقلية للتوسع في استخدامات الطاقة الثمسية .

\section{sall}

أمل جاسم: مولدات الطاقة وأثرها على البيئة، مجلة بيئتنا - الهيئة العامة للبيئة الكويت، العدد

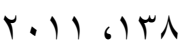

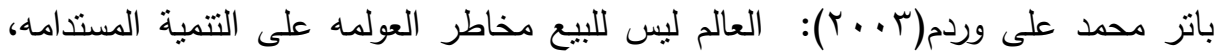

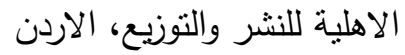

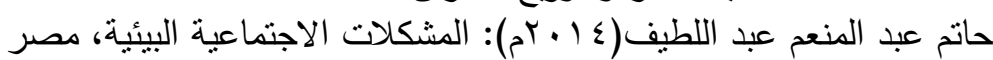

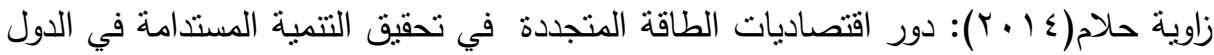

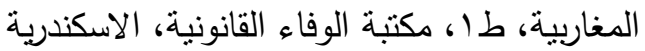

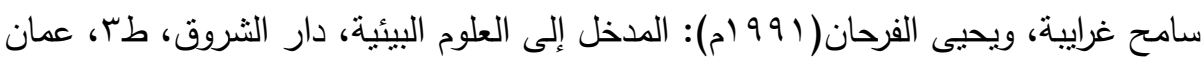

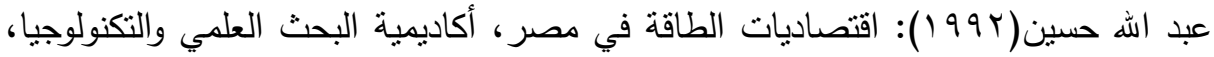
وزارة البحث العلمى، القاهرة

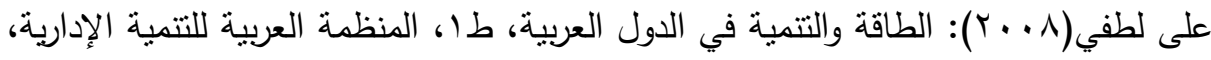

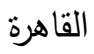

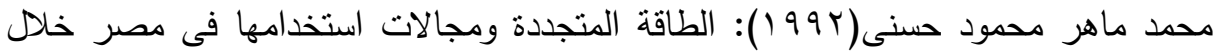

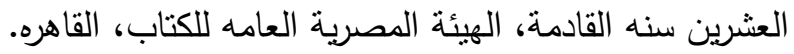

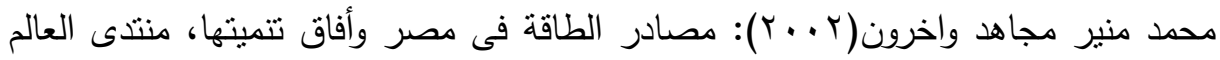

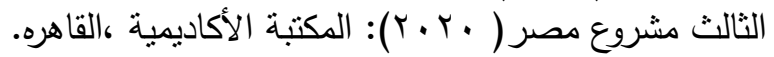

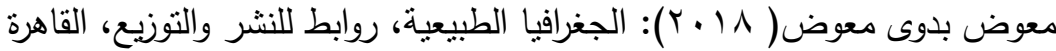

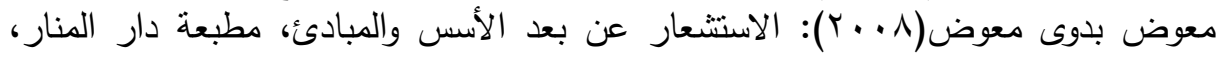
القاهرة

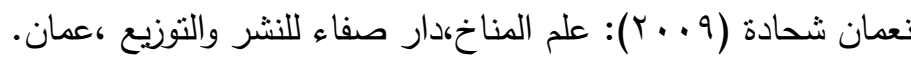

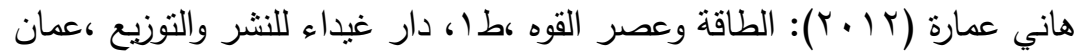

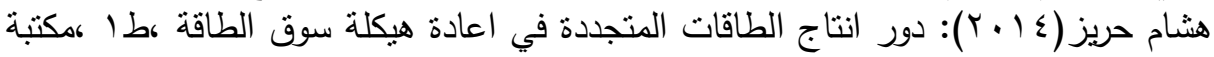
الوفاء القانونية، الاسكندرية التطات النات 
عبد العزيز عبد اللطيف وآخرون

Brussels (2006): Commission of the European Communities, GREEN PAPER - A European Strategy for Sustainable, Competitive and Secure Energy, 105 final.

Beat B, (2000): Principes écologique et sociaux du marché, économica, France, .

Fick, S.E., and Hijmans, R.J.(2017): Worldclim 2: New 1-km spatial resolution climate surfaces for global land areas. International Journal of Climatology.http://www.worldclim.org/(accessed 15-082017)

\title{
ENVIRONMENTAI IMPACTS OF THE USES OF SOLAR ENERGY IN EGYPT STUDY USING GIS AND REMOTE SENSING TECHNIQUES
}

Abdellatif, A. ${ }^{(1)}$; Moawad, M. B. ${ }^{(1)}$ and Mohammed, Hebatallah, F. 1) Faculty of Arts, Ain Shams University

\begin{abstract}
Solar energy is one of the most important energy resources in the world and is one of the most important sources of renewable energy because it is one of the main strategic options to meet the future needs of local and global energy, as it is available in most of the world. As well as it is a clean energy that does not pollute or harm the environment.

Distribution of solar energy on the surface of the earth varies according to earth rotation around the sun and the difference between the distances between them throughout the year .Thus, magnitude and intensity of solar radiation on the earth's surface varies greatly from one

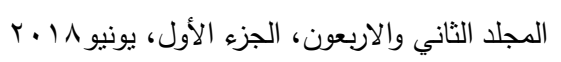


season to one another according to the distance between the earth and the sun distinguished by different incident angles throughout the day and the year. Density of the clouds plays an important role in obscuring and reducing amounts and intensity of solar radiation and hence it reduces amount of potential energy, which is revealed by maps of spatial distribute of solar radiation and maps of the potential energy in Egypt.

In this study factors affecting solar radiation were analyzed and the potentials energy was estimated. The study included the analysis a questionnaire of the solar energy companies of (20) companies to reach a number of objectives, including to reveal to what extent the Egyptian culture in the field of solar energy, especially from the trend of establishing solar power plants in Egypt and the use of solar energy in various areas instead of traditional energy, some of the obstacles faced by investors in the field of solar energy in Egypt and how to overcome these obstacles in the near future have been cleared from the questionnaire.

The questionnaire revealed as well that there is noticeable increase in using solar energy instead of conventional energy. Therefore, solar power stations are involved in a variety of activities such as industry, lighting, cooking, farming, water pumping,...etc. These activities ascertain the importance of solar energy to achieve sustainable development and environmental security. In that manner, the future strategic plan of Egypt, which known as 2030, mainly emphasizes on increasing usage of renewable energy generally, and solar energy in specific in the major projects. 